\title{
High pressure studies on the electrical resistivity of As-Te-bond Si glasses and the effect of network topological thresholds
}

\author{
Deepti Verma, B.H. Sharmila, K. Rukmani \& S. Asokan
}

To cite this article: Deepti Verma, B.H. Sharmila , K. Rukmani \& S. Asokan (2008) High pressure studies on the electrical resistivity of As-Te-bond Si glasses and the effect of network topological thresholds, High Pressure Research, 28:1, 55-62, DOI: 10.1080/08957950701782569

To link to this article: http://dx.doi.org/10.1080/08957950701782569

曲 Published online: 10 Mar 2008.

Submit your article to this journal $[\pi$

Џll Article views: 23

Q View related articles $\longleftarrow$

Citing articles: 2 View citing articles $\longleftarrow$ 


\title{
High pressure studies on the electrical resistivity of $\mathrm{As}-\mathrm{Te}-\mathrm{Si}$ glasses and the effect of network topological thresholds
}

\author{
Deepti Verma ${ }^{\mathrm{a}}$, B.H. Sharmila ${ }^{\mathrm{b}}$, K. Rukmani ${ }^{\mathrm{c}}$ and S. Asokan ${ }^{\mathrm{b} *}$ \\ ${ }^{a}$ Department of Physics, M.S. Ramaiah Degree College, Bangalore, India $;{ }^{b}$ Department of \\ Instrumentation, Indian Institute of Science, Bangalore, India; ${ }^{c}$ Department of Physics, Bangalore \\ University, Bangalore, India
}

(Received 14 February 2007; final version received 02 November 2007)

\begin{abstract}
The variation of resistivity in an amorphous $\mathrm{As}_{30} \mathrm{Te}_{70-x} \mathrm{Si}_{x}$ system of glasses with high pressure has been studied for pressures up to $8 \mathrm{GPa}$. It is found that the electrical resistivity and the conduction activation energy decrease continuously with increase in pressure, and samples become metallic in the pressure range 1.0-2.0 GPa. Temperature variation studies carried out at a pressure of $0.92 \mathrm{GPa}$ show that the activation energies lie in the range $0.16-0.18 \mathrm{eV}$. Studies on the composition/average co-ordination number $\langle r\rangle$ dependence of normalized electrical resistivity at different pressures indicate that rigidity percolation is extended, the onset of the intermediate phase is around $\langle r\rangle=2.44$, and completion at $\langle r\rangle=2.56$, respectively, while the chemical threshold is at $\langle r\rangle=2.67$. These results compare favorably with those obtained from electrical switching and differential scanning calorimetric studies.
\end{abstract}

Keywords: chalcogenides; high pressure; electrical resistivity; topological thresholds

PACS: $71.23 \mathrm{Cq} ; 71.55 \mathrm{Jv} ; 72.15 \mathrm{Cz} ; 72.80 \mathrm{Ng}$

\section{Introduction}

High pressure-induced metallization and crystallization in glassy semiconductors occur discontinuously in some glasses, and continuously in others. It is found that IV-VI chalcogenide glasses exhibit sharp, discontinuous glassy semiconductor to crystalline metal transition around 5-8 GPa $[1,2]$. On the other hand, III-VI [3, 4] and V-VI [5] glasses such as Ga-Te and As-Te show continuous metallization under pressure. Further V-VI chalcogenide glasses are usually found to remain a semiconductor even up to $10 \mathrm{GPa}[5,6]$. The ternary glass $\mathrm{As}-\mathrm{Te}-\mathrm{In}$ has been found to undergo metallization continuously [7] under pressure. The effect of pressure on a ternary glass such as $\mathrm{As}-\mathrm{Te}-\mathrm{Si}$ is therefore of considerable interest.

Composition dependence of various properties of chalcogenide glasses reveal the existence of two topological thresholds: rigidity percolation threshold (RPT) and chemical threshold (CT). According to Phillips and Thorpe [8-10], the local structure and network rigidity of chalcogenide glasses is composition-dependant, and a floppy to rigid transformation in network chalcogenide

*Corresponding author. Email: sasokan@isu.iisc.ernet.in

ISSN 0895-7959 print/ISSN 1477-2299 online

(C) 2008 Taylor \& Francis

DOI: $10.1080 / 08957950701782569$

http://www.informaworld.com 
glasses - the RPT - may be identified. Recent ideas of Boolchand et al. [11-13] suggest that the floppy to rigid transition is not sharp as considered earlier but that the network goes through an intermediate regime where both floppy and rigid networks coexist. The two ends of the intermediate regime indicate the onset of rigidity percolation and its completion. In addition to a mechanical threshold, there is also a CT in chalcogenide glasses at the critical composition at which the covalent random network becomes completely heteropolar.

The present work reports electrical resistivity measurements on bulk $\mathrm{As}-\mathrm{Te}-\mathrm{Si}$ glasses at high pressure and attempts to understand the effect of topological thresholds on the high pressure behavior of these samples.

\section{Experimental details}

Bulk semi-conducting glasses of an $\mathrm{As}_{30} \mathrm{Te}_{70-x} \mathrm{Si}_{x}$ system with $5 \leq x \leq 22$ were prepared by the conventional melt quenching method. Appropriate quantities of pure elements (99.999\%) of As, $\mathrm{Te}$, and $\mathrm{Si}$ were weighed to $0.1 \mathrm{mg}$ accuracy and vacuum-sealed in evacuated quartz ampoules at $10^{-5}$ Torr and slowly heated in the horizontal rotary furnace to $1140^{\circ} \mathrm{C}$ at the rate of $1000 \mathrm{C} / \mathrm{h}$. The ampoules were maintained at $1140^{\circ} \mathrm{C}$ and were continuously rotated for about $24 \mathrm{~h}$ at $10 \mathrm{rpm}$ to ensure homogeneity of the melt. The ampoules were subsequently quenched in a bath of ice water and $\mathrm{NaOH}$ mixture. The amorphous nature of the samples was confirmed by $\mathrm{X}$-ray diffraction (XRD).

Electrical resistivity measurements at high pressures of up to $8 \mathrm{GPa}$ have been carried out in a Bridgman anvil cell with a working face diameter of $12 \mathrm{~mm}$. The design of the anvil is as reported in ref. [14] and is made of tungsten carbide and provided with alloy steel (EN24) binding rings. Pyrophyllite gaskets of $0.31 \mathrm{~mm}$ critical thickness were used in split gasket configuration. Steatite was used as the quasi-hydrostatic pressure-transmitting medium. Bismuth has been employed as an in situ pressure calibrant in all the resistivity runs. Samples of approximate dimension $2 \mathrm{~mm} \times 1.5 \mathrm{~mm} \times 0.2 \mathrm{~mm}$ were used for the present measurements of resistivity under pressure. The resistances of samples were measured using a Keithley 614 electrometer. After pressurization, the samples were recovered from the pressure cell and XRD studies were carried out to find the structure of the high pressure phase. Resistivity measurements were also undertaken at low temperatures $(300-80 \mathrm{~K})$ and different pressures using a Fugi-Nagano [15] type continuous pressure changing system and an anvil with a working face diameter of $6 \mathrm{~mm}$.

\section{Results}

The effect of pressure on the resistivity behavior of all samples studied in the ternary series $\mathrm{As}_{30} \mathrm{Te}_{70-x} \mathrm{Si}_{x}$ is similar, and the normalized electrical resistivity shows a continuous decrease, with metallization around 1.0-2.0 GPa. Figures 1-3 show the variation of normalized electrical resistivity with pressure. Here $\rho_{a}$ is the resistivity at ambient pressure and is of the order of $10^{6} \Omega$-cm. Figure 4 shows the temperature variation of the normalized resistivity at different constant pressures in some representative samples. It can be seen from Figure 4 that at pressures lower than $1.0 \mathrm{GPa}$, the normalized resistivity obeys the Arrhenius relation $\rho=\rho_{0} \exp (\Delta E / k T)$, where $\rho_{0}$ is the pre-exponential factor, $k$ is the Boltzmann constant, and $\Delta E$ is the activation energy for electrical conduction.

The conductivity activation energy, $\Delta E$, is estimated from the slope of the temperature dependence of resistivity $\left(\log \rho / \rho_{a}\right.$ versus $\left.1000 / T\right)$ and is in the range $0.3-0.22 \mathrm{eV}$ at ambient pressure. At a pressure of $0.92 \mathrm{GPa}$, the activation energies have reduced to about $0.16-0.18 \mathrm{eV}$. 


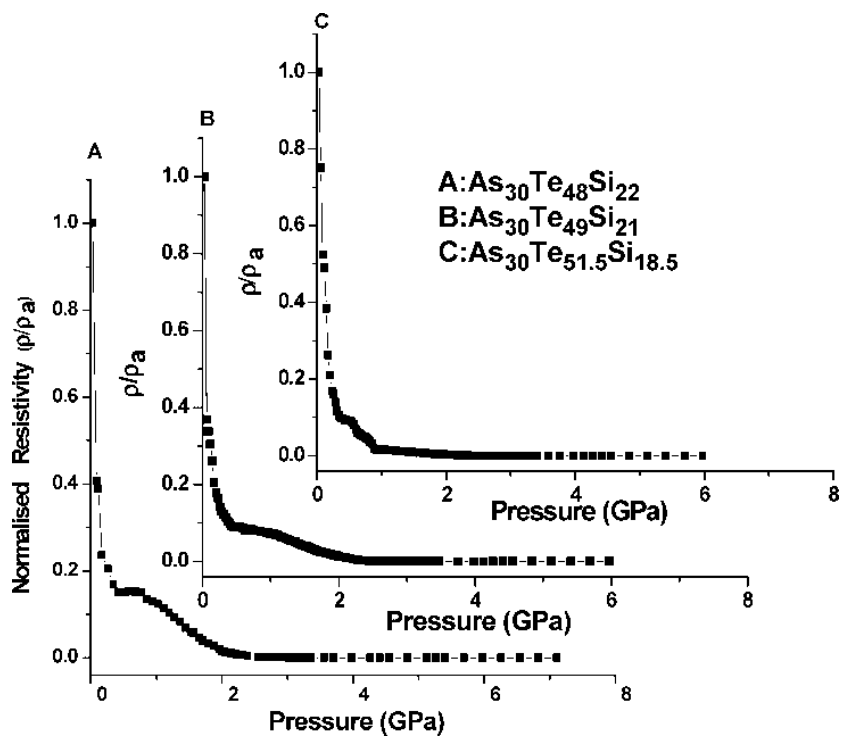

Figure 1. Variation of the normalized electrical resistivity with pressure for $\mathrm{As}_{30} \mathrm{Te}_{48} \mathrm{Si}_{22}, \mathrm{As}_{30} \mathrm{Te}_{49} \mathrm{Si}_{21}$ and $\mathrm{As}_{30} \mathrm{Te}_{51.5} \mathrm{Si}_{18.5}$.

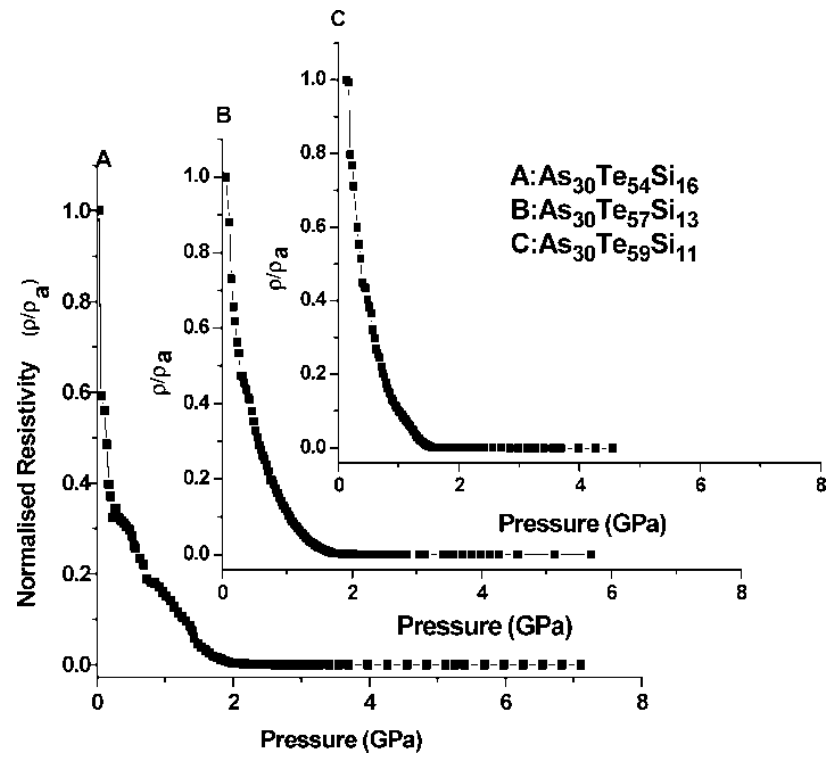

Figure 2. Variation of the normalized electrical resistivity with pressure for $\mathrm{As}_{30} \mathrm{Te}_{54} \mathrm{Si}_{16}, \mathrm{As}_{30} \mathrm{Te}_{57} \mathrm{Si}_{13}$ and $\mathrm{As}_{30} \mathrm{Te}_{59} \mathrm{Si}_{11}$ glasses.

Figure 5 shows the change in activation energy with pressure for two representative samples $\mathrm{As}_{30} \mathrm{Te}_{48} \mathrm{Si}_{22}$ and $\mathrm{As}_{30} \mathrm{Te}_{62} \mathrm{Si}_{8}$. It can be seen that the activation energy decreases with pressure, indicating that the metallic state of the sample at high pressures is attained due to the decrease in energy gap at these pressures. The effect of pressure is to mainly reduce the interatomic distance leading to an increase in the mobility of the electrons. This increases the conductivity, or in other words, the resistivity is reduced. 


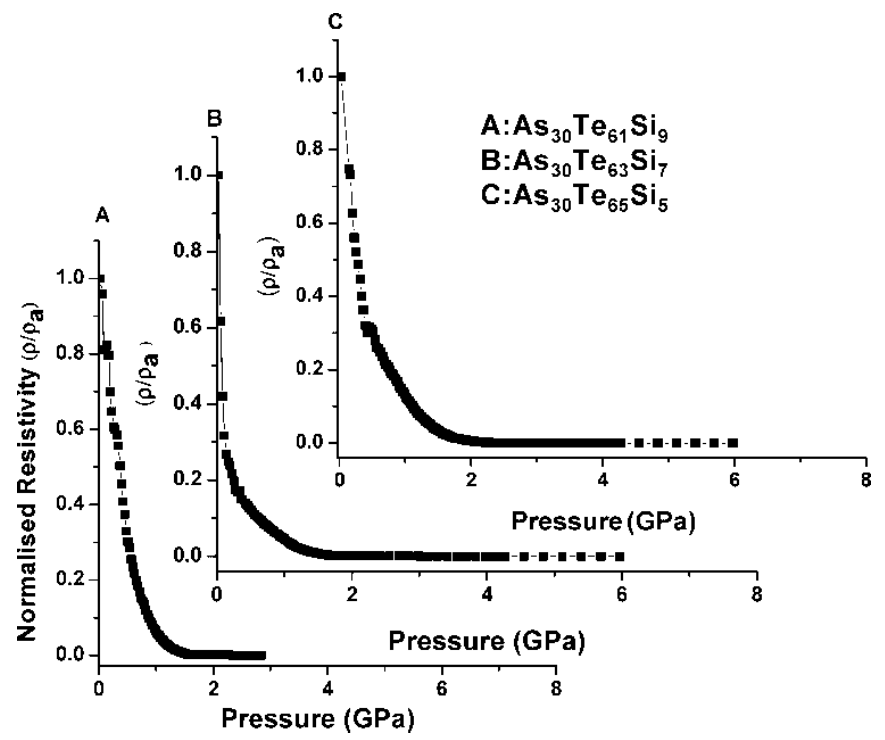

Figure 3. Variation of the normalized electrical resistivity with pressure for $\mathrm{As}_{30} \mathrm{Te}_{61} \mathrm{Si}_{19}, \mathrm{As}_{30} \mathrm{Te}_{63} \mathrm{Si}_{7}$ and $\mathrm{As}_{30} \mathrm{Te}_{65} \mathrm{Si}_{5}$ glasses.
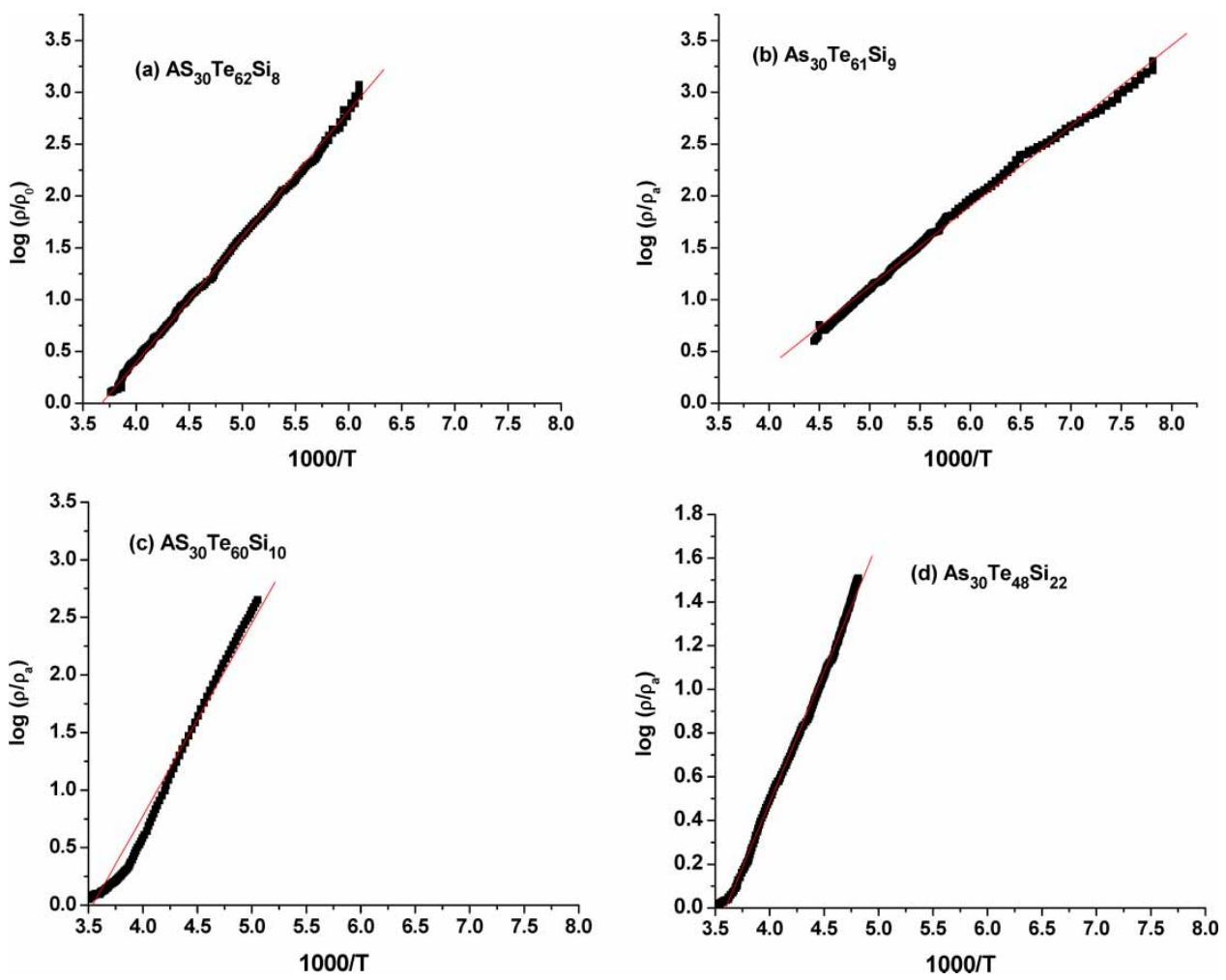

Figure 4. Variation of $\log \left(\rho / \rho_{a}\right)$ with $(1000 / T)$ for (a) $\mathrm{As}_{30} \mathrm{Te}_{62} \mathrm{Si}_{8}$ (b) $\mathrm{As}_{30} \mathrm{Te}_{61} \mathrm{Si}_{9}$ (c) $\mathrm{As}_{30} \mathrm{Te}_{60} \mathrm{Si}_{10}(\mathrm{~d}) \mathrm{As}_{30} \mathrm{Te}_{48} \mathrm{Si}_{22}$ glasses at a pressure of $0.92 \mathrm{GPa}$. 


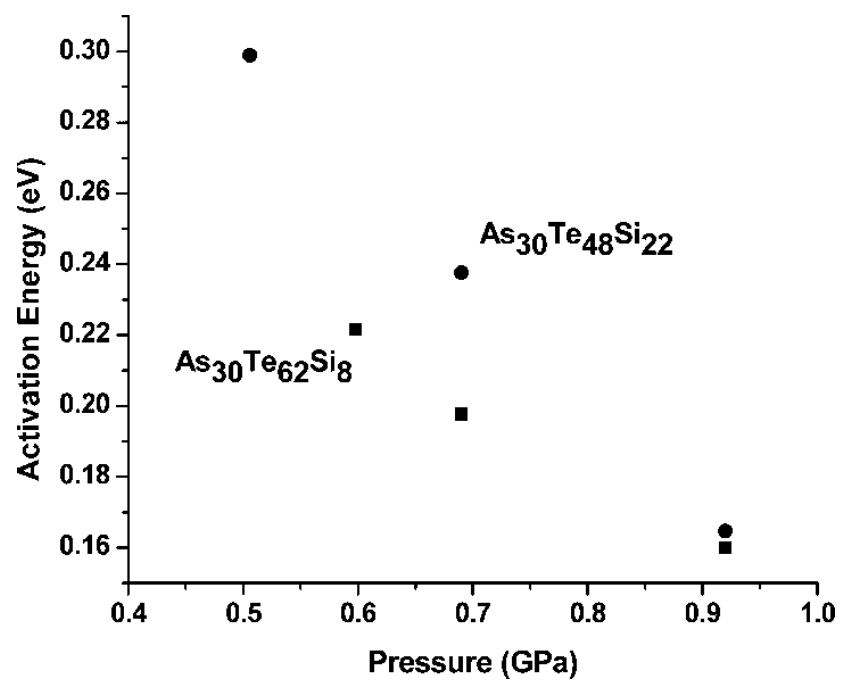

Figure 5. Variation of activation energy with pressure in $\mathrm{As}_{30} \mathrm{Te}_{48} \mathrm{Si}_{22}$ and $\mathrm{As}_{30} \mathrm{Te}_{62} \mathrm{Si}_{8}$ glasses.

\section{Discussion}

\subsection{Influence of topological threshold on the high pressure resistivity of As-Te-Si glasses}

The composition dependence of normalized resistivity at two representative pressures, $0.5 \mathrm{GPa}$ and $1.0 \mathrm{GPa}$, is shown in Figures 6(A) and 6(B). Assuming the 8-N rule, one can assign a coordination number of 3 to As, 2 to Te, and 4 to Si. It is reasonable to assume that silicon exists in 4 co-ordination even though other metals such as Al have been known to possess higher co-ordination.

With these assumptions it is possible to calculate an average co-ordination $\langle r\rangle$ for the different compositions. These $\langle r\rangle$ values are also plotted in Figures 6(A) and 6(B) for comparison with the literature $[16,17]$.
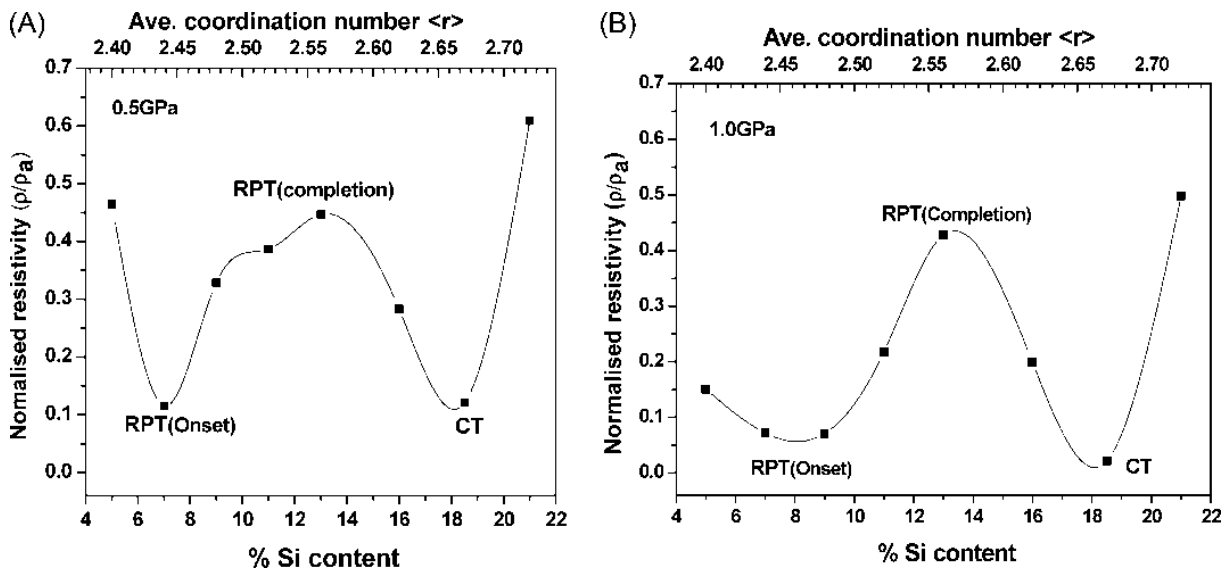

Figure 6(A). Variation of normalized electrical resistivity with silicon content/average co-ordination number $\langle r\rangle$ at a pressure of $0.5 \mathrm{GPa}$. Figure 6(B). Variation of normalized electrical resistivity with silicon content/average co-ordination number $\langle r\rangle$ at a pressure of $1.0 \mathrm{GPa}$. 
The normalized electrical resistivity exhibits an initial decrease with silicon content as seen in Figures 6(A) and 6(B). Around $x=7(\langle r\rangle=2.44),\left(\rho / \rho_{a}\right)$ starts increasing with silicon content, reaching a local maximum around $x=13(\langle r\rangle=2.56)$. Beyond this composition, a decrease is seen in $\rho / \rho_{a}$ which culminates in a local minimum around $x=18.5(\langle r\rangle=2.67)$.

Chalcogenide glasses have been known to undergo a transition from floppy polymeric glass to a rigid amorphous solid at RPT [8-10]. In some glasses, the rigidity percolation is seen to span over a range of compositions $[12,13]$ with the occurrence of two transitions, a floppy to isostatically rigid state and then an isostatically rigid to stressed rigid state. Glass compositions residing between the floppy and the stressed rigid phases constitute the intermediate phase, forming space filling networks with lower molar volumes.

Normalized resistivity measurements at high pressures [7] in the two tie-lines $\mathrm{As}_{40} \mathrm{Te}_{60-x} \mathrm{In}_{x}$ $(5 \leq x \leq 17.5)$ and $\mathrm{As}_{30} \mathrm{Te}_{70-x} \operatorname{In}_{x}(10 \leq x \leq 17.5)$ as a function of composition have reported features similar to the series reported in this paper. They have identified the minimum observed at $\langle r\rangle=2.65(x=12.5)$ with RPT and the minimum at $\langle r\rangle=2.7(x=15)$ with CT. Modulated differential scanning calorimetric measurements on the As-Te-In system [18] also indicate RPT at $\langle r\rangle=2.65$ and $\mathrm{CT}$ at $\langle r\rangle=2.7$. No signature of the intermediate phase was found in these glasses.

Electrical switching studies on $\mathrm{As}-\mathrm{Te}-\mathrm{Si}$ glasses [16], the two tie-lines investigated being $\mathrm{As}_{30} \mathrm{Te}_{70-x} \mathrm{Si}_{x}(2 \leq x \leq 22)$ and $\mathrm{As}_{40} \mathrm{Te}_{60-x} \mathrm{Si}_{x}(2 \leq x \leq 17)$, indicate a sharp slope change in the switching voltage, $V_{t}$, at $\langle r\rangle=2.46$, which is associated with rigidity percolation, and a local minimum at $\langle r\rangle=2.66$, which is identified with CT. For the series $\mathrm{As}_{30} \mathrm{Te}_{70-x} \mathrm{Si}_{x}$, the reported values of the silicon percentage are $x=8$ and $x=18$ for RPT and CT respectively.

Differential scanning calorimetric studies [17] on the series $\mathrm{As}_{40} \mathrm{Te}_{60-x} \mathrm{Si}_{x}(2 \leq x \leq 17)$, giving the variation with composition of the first crystallization temperature, $\Delta T$, the difference between first crystallization temperature and glass transition temperature, and the change in the specific heat capacity $(\triangle C p)$ during glass transition, suggest an extended stiffness transition in this system. The compositions $x=4$ and $x=8$ have been identified as the onset and completion of the intermediate phase while CT is suggested to occur at $x=12$. The average co-ordination numbers corresponding to these would be $\langle r\rangle=2.48$ and $\langle r\rangle=2.56$ for the onset and completion of the intermediate phase and $\langle r\rangle=2.64$ for CT respectively.

Comparing these results with the composition dependence of electrical resistivity at high pressure in $\mathrm{As}_{30} \mathrm{Te}_{70-x} \mathrm{Si}_{x}$, shown in Figures 6(A)(a) and 6(A)(b), the change in trend at $x=7$ $(\langle r\rangle=2.44)$ and maximum at $x=13(\langle r\rangle=2.56)$ may be identified with the onset and completion of the rigidity percolation, with the composition range $7 \leq x \leq 13$ representing the intermediate phase. The local minimum at $x=18.5(\langle r\rangle=2.67)$ may be suggestive of CT.

Electrical resistivity is a macroscopic probe and the micro dynamics of the system, such as the structural units formed under pressure, cannot be seen in these measurements. However, correlation with differential scanning calorimetry results allows identification of onset and completion of RPT at $x=7$ and $x=13$, respectively.

As the composition is varied, the addition of Si having higher co-ordination at the expense of Te having lower co-ordination leads to an increase in network connectivity thereby reaching the rigidity thresholds. The main structural units expected to be formed in this system are $\mathrm{As}\left(\mathrm{Te}_{1 / 2}\right)_{3}$ pyramids, $\mathrm{Si}\left(\mathrm{Te}_{1 / 2}\right)_{4}$ tetrahedra and Te chains. Units of the type $\mathrm{SiAs}_{2}$ have also been seen in the $\mathrm{XRD}$ of the samples recovered after pressurization. The possibility of formation of $\mathrm{Te}=\mathrm{As}\left(\mathrm{Te}_{1 / 2}\right)_{3}$ quasi tetrahedral units, where As has 5-coordination, and $\mathrm{As}-\mathrm{Si}$ and $\mathrm{SiAs}_{2}$ type units may be the reason for the existence of the intermediate phase. Further experiments using microscopic probes such as high pressure Raman may be needed to understand the details of microscopic dynamics.

It is nevertheless of interest to note that electrical resistivity at high pressures shows a composition dependence where the percolation thresholds can be identified and region of the extended transition be observed. 


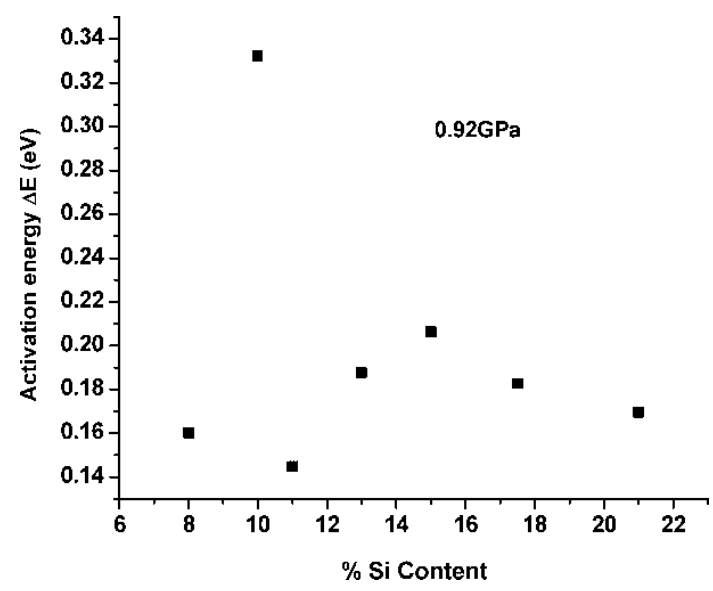

Figure 7. Variation of activation energy with percentage silicon content at a pressure of $0.92 \mathrm{GPa}$.

Table 1. Peaks in the XRD after pressurization cycle.

\begin{tabular}{ll}
\hline Composition & \multicolumn{1}{c}{ Peaks present } \\
\hline $\mathrm{As}_{30} \mathrm{Te}_{63} \mathrm{Si}_{7}$ & $\mathrm{As}_{2} \mathrm{Te}_{3}, \mathrm{AsSi}$ \\
$\mathrm{As}_{30} \mathrm{Te}_{61} \mathrm{Si}_{9}$ & $\mathrm{Large} \mathrm{As}_{2} \mathrm{Te}_{3}$, small AsSi \\
$\mathrm{As}_{30} \mathrm{Te}_{55} \mathrm{Si}_{15}$ & No peaks in X-ray \\
$\mathrm{As}_{30} \mathrm{Te}_{49} \mathrm{Si}_{21}$ & Two peaks of As $\mathrm{Te}_{3}$ (different orientations), $\mathrm{SiAs}_{2}$ \\
\hline
\end{tabular}

Figure 7 shows the variation of activation energy with silicon content at a pressure of $0.92 \mathrm{GPa}$. Though some variation in the activation energy is seen, no signature of the intermediate phase (RPT) or of CT is observed.

\subsection{Metallization and crystallization of As-Te-Si glasses under pressure}

As-Te-Si samples were recovered from the anvil cell after being subjected to high pressure using $\mathrm{NaCl}$ as the pressure-transmitting material. The pressurized sample was collected by dissolving $\mathrm{NaCl}$ in distilled water. X-ray crystallographic data was collected on four representative compositions after a cycle of pressurization, and the peaks seen in the XRD data are given in Table 1.

It was also observed that the sample with the highest $\mathrm{Si}$ content reverted to the semi-conducting state when pressure was released. The resistivity behavior on applying pressure again was similar to the first time and started at a slightly reduced value. This implies that the sample does not undergo complete crystallization at the high pressures applied.

\section{Conclusions}

Bulk As $-\mathrm{Te}-\mathrm{Si}$ glasses are found to exhibit a continuous decrease in electrical resistivity and conductivity activation energy with pressure, and samples become metallic in pressure range 1.0-2.0 GPa. The composition dependence of normalized electrical resistivity at different pressures indicates an extended stiffness transition with the onset of the intermediate phase around the average co-ordination $\langle r\rangle=2.44(x=7)$ and completion around $\langle r\rangle=2.56(x=13)$ and CT occurring around the average co-ordination of $\langle r\rangle=2.67(x=18.5)$. These results are in close agreement with those obtained from electrical switching studies and differential scanning calorimetry. 


\section{Acknowledgements}

Deepti Verma is grateful to M. Anbarasu for valuable help and management of M.S. Ramaiah College for their support and encouragement.

\section{References}

[1] S. Asokan, E.S.R. Gopal, and G. Parthasarathy, J. Mater. Sci. 21 (1986), p. 625.

[2] G. Parthasarathy et al., Solid State Commun. 51(1984), p. 195.

[3] G. Parthasarathy et al., J. Mater. Sci. 5 (1986), p. 809.

[4] G. Parthasarathy et al., Phys. Lett. A 131 (1988), p. 441.

[5] S.S.K. Titus et al., Phil. Mag. B 62 (1990), p. 553.

[6] S.S.K. Titus, S. Asokan, and E.S.R. Gopal, High Press. Res. 10 (1992), p. 629.

[7] B.H. Sharmila, J.T. Devaraju, and S. Asokan, J. Non-Cryst. Solids 303 (2002), p. 372.

[8] J.C. Phillips and M.F. Thorpe, Solid State Commun. 53 (1985), p. 699.

[9] J.C. Phillips, Phys. Rev B 31 (1985), p. 8157.

[10] M.F. Thorpe, J. Non-Cryst. Solids 57 (1983), p. 355.

[11] D. Selvanathan, W.J. Bresser, and P. Boolchand, Phys. Rev. B 61 (2000), p. 15061.

[12] P. Boolchand, J. Optoelect. Adv. Mater. 3 (2001), p. 703.

[13] D.G. Georgiev, P. Boolchand, and M. Micoulaut, Phy. Rev. B 62 (2000), p. R9228.

[14] A.K. Bandhopadhyay et al., Rev. Sci. Instrum. 51 (1980), p. 136.

[15] G. Fuji and H. Nagano, Cryogenics 11 (1971), p. 142.

[16] M. Anbarasu and S. Asokan, Appl. Phys. A 80 (2005), p. 249.

[17] - J. Non-Cryst. Solids 35 (2006), p. 1551.

[18] B.H. Sharmila, J.T. Devaraju, and S. Asokan, J. Non-Cryst. Solids 326, 327 (2003), p. 154. 